\title{
SURGICAL TREATMENT OF HYDATID DISEASE OF CENTRAL NERVOUS SYSTEM - OUR EXPERIENCE AND REVIEW OF THE LITERATURE
}

\author{
St. Valkanov ${ }^{1 *}$, I. Chakarov ${ }^{2}$, Ts. Popkharitov ${ }^{1}$, A. Popkharitov ${ }^{1}$, B. Chakarova ${ }^{3}$, \\ P. Chakarova ${ }^{2}$, P. Valkanov ${ }^{1}$, B. Petrov ${ }^{1}$, I. Mindov \\ ${ }^{1}$ Department of Surgery, Neurosurgery and Urology, Medical Faculty, Trakia University, \\ Stara Zagora, Bulgaria \\ ${ }^{2}$ Department of Pediatrics, Medical Faculty, Trakia University, Stara Zagora, Bulgaria \\ ${ }^{3}$ Department of Hygiene, Epidemiology, Infectious \& Parasitic Diseases, Medical Faculty, \\ Trakia University, Stara Zagora, Bulgaria
}

\begin{abstract}
Introduction: Echinococcosis is a widespread parasitic disease of humans caused by the larval stages of Echinococcus granulosus. The involvement of CNS is relatively rare and therefore its clinical diagnosis is often difficult. Cerebral hydatid disease represents about $2-4 \%$ of all cases of echinococcosis, while the incidence of echinococcosis among space-occupying lesions of the brain varies between different countries and may reach $1.6-2.8 \%$. The hydatid disease of the spine occurs in $1 \%$ of hydatidosis and is mostly located in the thoracic spine. Solitary affection of both the brain and the spine is an exception. Materials and methods: Eight patients with hydatid disease of CNS were surgically treated for a 10 years period. Six of them were with cerebral echinococcosis, in one case it is a primary echinococcus cyst and 2 patients with spinal hydatid disease - in one of the cases there is a rare cervico-occipital localization of the cyst. In all cases the diagnosis was made late and the patients were in serious overall condition and pronounced neurological deficit. Discussion: Cerebral hydatid disease is a rare type of space-occupying lesions of the brain. It occurs 2-3 times more common in children than in adults. In the majority of cases, cerebral echinococcosis is accompanied by lesions in lung or liver. Isolated affection is an exception. In a diagnostic term the cerebral hydatid cysts presents with characteristic features on preoperative cerebral CT scans and are therefore easily diagnosed. However, in many cases the diagnosis comes late, after exhaustion of adaptation capabilities of the brain. The reason for this must be observed in the absence of echinococcosis in differential diagnostic term of thinking mainly because of its rarity. Surgical resection is the therapy of choice in both the cerebral and spinal echinococcosis. Accurate preoperative diagnosis is essential, as intra-operative rupture of the cyst will result in spreading of the disease.
\end{abstract}

Key words: cerebral echinococcosis, spinal echinococcosis

\section{INTRODUCTION}

Echinococcosis is a widespread parasitic disease of humans caused by the larval stages of Echinococcus granulosus. The hydatid disease most frequently occurs in the endemic areas such as Europe, Russia, China, North America, Australia, New Zealand and the Mediterranean - Bulgaria, Rumania, Greece, Turkey [1]. In Europe in 2011 a total of 784 confirmed cases of human echinococcosis were reported by 26 of the 30 EU/EEA countries. The notification rate of

\footnotetext{
*Correspondence to: St. Valkanov, Department of Neurosurgery, Medical Faculty, Trakia University, Armeiska str, 6000, Stara Zagora, Bulgaria, Tel: +359887558275,E-mail:nhk_stz@yahoo.com.
}

echinococcosis in the EU was 0.18 cases per 100000 population. Four countries (Bulgaria, Germany, Spain and Romania) accounted for $70.6 \%$ of all confirmed cases reported in 2011. Bulgaria had the highest confirmed case rate (4.09 cases per 100000 population or 307 confirmed cases $-39,1 \%$ of the total number reported), more than 20 times the EU average [2 -7]. Nevertheless the involvement of CNS is relatively rare and therefore its clinical diagnosis is often difficult. Liver (50-77\%) and lung ( 8.5 to $43 \%$ ) are the organs affected most frequently by the disease $[8,9]$. Cerebral hydatid disease represents about $2-4 \%$ of all cases of echinococcosis [10], while the incidence of echinococcosis among spaceoccupying lesions of the brain varies between different countries and may reach 1.6-2.8\% 
$[11,12]$. The hydatid disease of the spine occurs in $1 \%$ of hydatidosis and is mostly located in the thoracic spine [13-18]. In the majority of cases, cerebral echinococcosis is accompanied by lesions in lung or liver. Solitary affection of both the brain and the spine is an exception [11, 13, 19]. Cerebral echinococcosis is generally caused by hematogenic spreading of echinococcal larves forming primary hydatid cysts, predominantly located in the territory of the internal carotid artery [20]. Hydatid disease of the spine either occurs by direct extension from a pulmonary infestation [21], or less commonly begins as primary affects the vertebral body [15]. Isolated spinal epidural hydatid cysts are extremely rare [21, 22].

\section{MATERIALS AND METHODS}

Eight patients with hydatid disease of CNS were surgically treated for a 10 years period. Six of them were with cerebral echinococcosis, in one case it is a primary echinococcus cyst and 2 patients with spinal hydatid disease - in one of the cases there is a rare cervico-occipital
ST. VALKANOV et al. localization of the cyst. All patients have a positive history of contact with stray dogs.

In 5 of the cases with intracranial hydatid cyst location, the patients were in childhood (8 to 16 years). In all cases the diagnosis was made late and the patients were in serious overall condition and pronounced neurological deficit.

In 4 of them the disease is manifested by tonicclonic convulsions and loss of consciousness and 2 of them develops symptoms of brain wedging. In all cases CT scans established a large, homogeneous spherical lesion with sharply circumscribed borders, having a significant mass effect and no pericystic edema (Figure 1). All of the patients were surgically treated. The lesions were removed by a large craniotomy over the topic of the process (Figure 2) without intraoperative rupture. Special attention was paid to the prevention of traumatic rupture of the cyst. It's liquid content was evacuated by puncture- aspiration, then the capsule was removed (Figure 3).

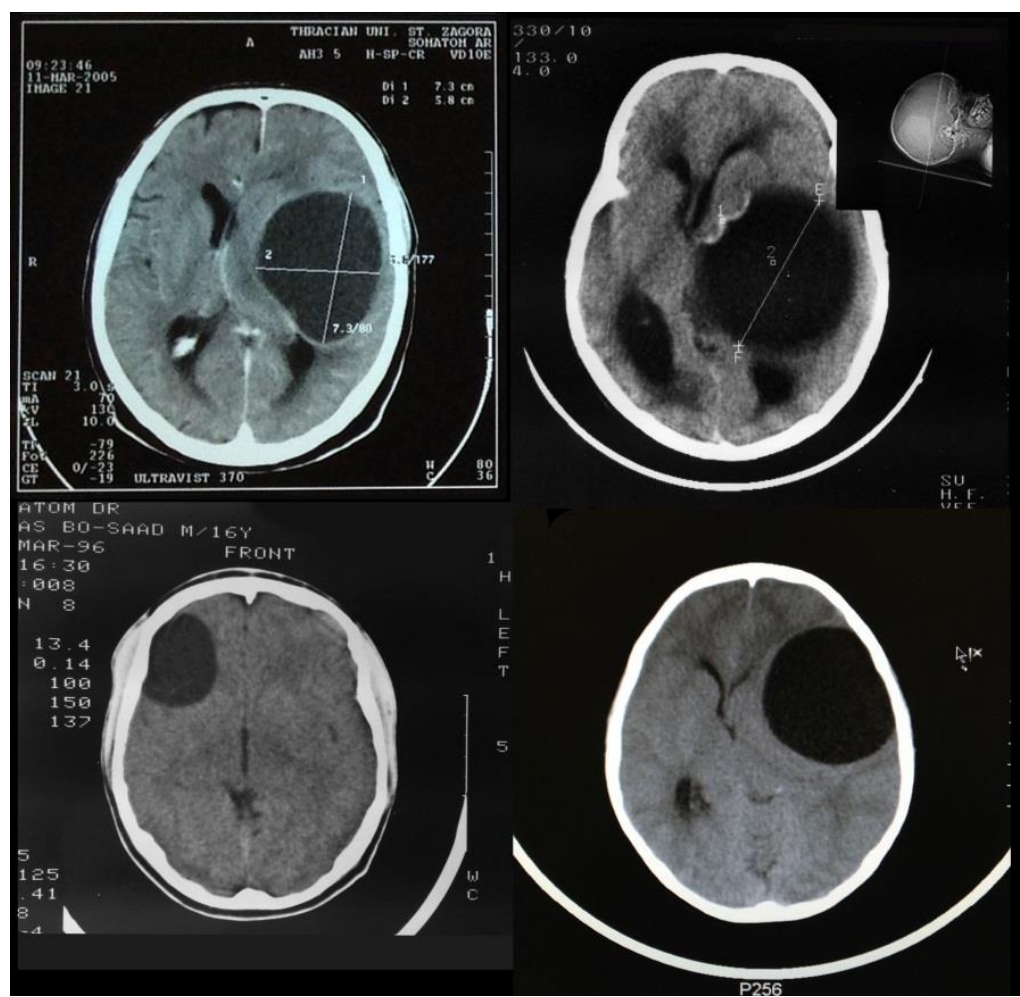

Figure 1. CT scans of 4 cases of cerebral echinococcosis. The cysts presents as huge spherical, homogenous lesions with clearly defined borders, a considerable mass effect but no relevant perifocal edema

In the case of cervico-occipital location of the cyst, 25-year-old patient was admitted because of rapidly growing (for a few months) pain and swelling in the left occipital-cervical region with limited movements of the neck and periodic shooting pains and numbness in the left cervical area and left shoulder. Clinical examination of the patient was normal, as well as routine laboratory findings. Left-sided cervico-brachial radiculopathy was found from the neurological status. Radiological investigations of the head and neck showed a slight destruction of the transverse processes of the upper cervical vertebrae and occipital bone on the left. The lesion was totally removed enbloc without rupturing. 


\section{ST. VALKANOV et al.}

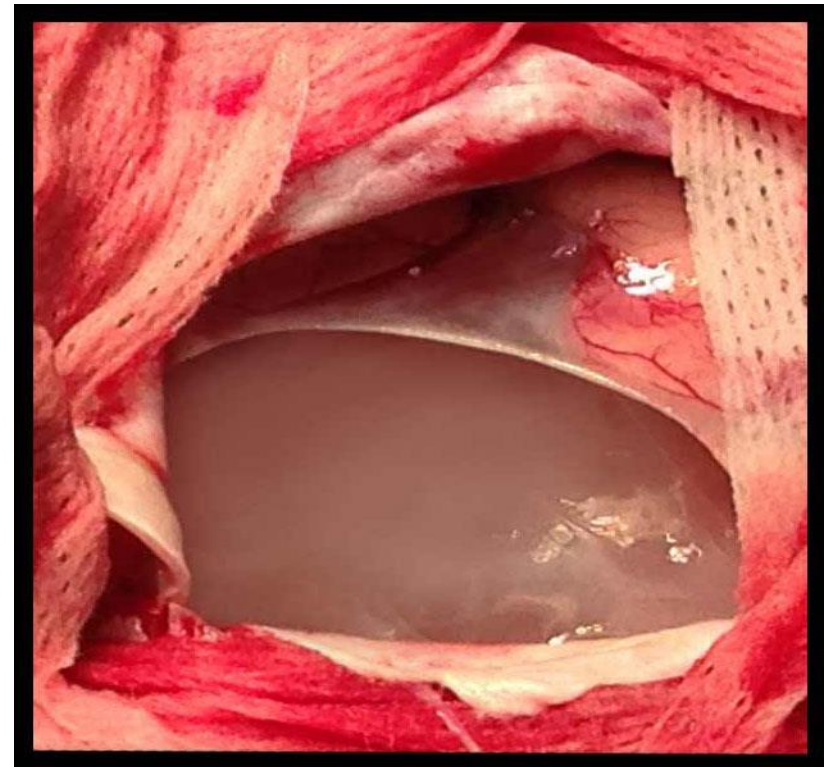

Figure 2. Intraoperative finding after a large craniotomy over the topic of the process.

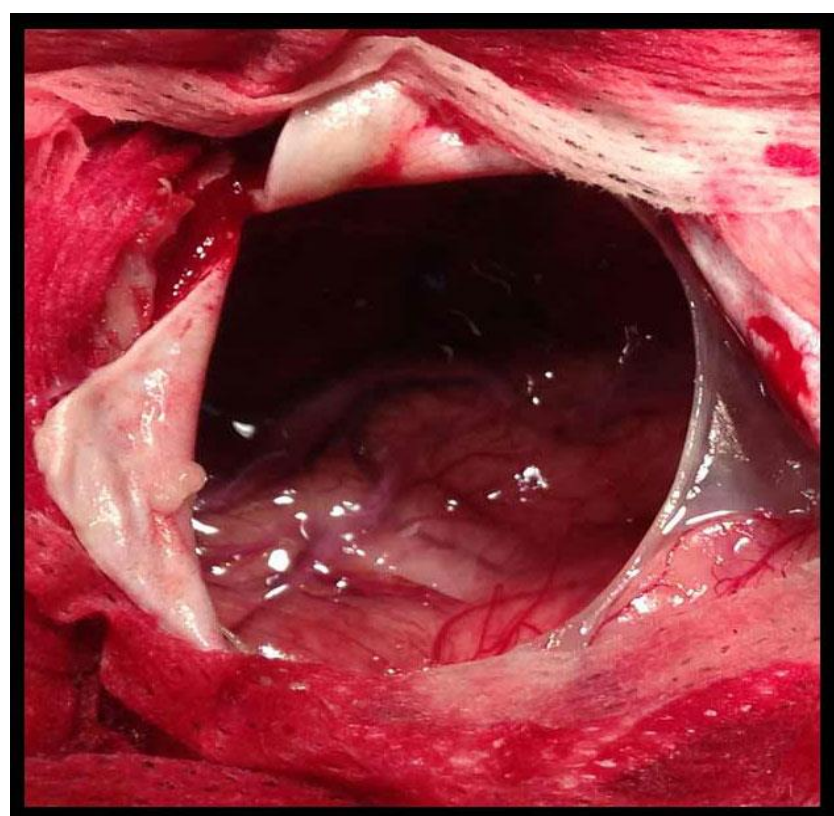

Figure 3. Brain hemisphere after removing of the cyst.

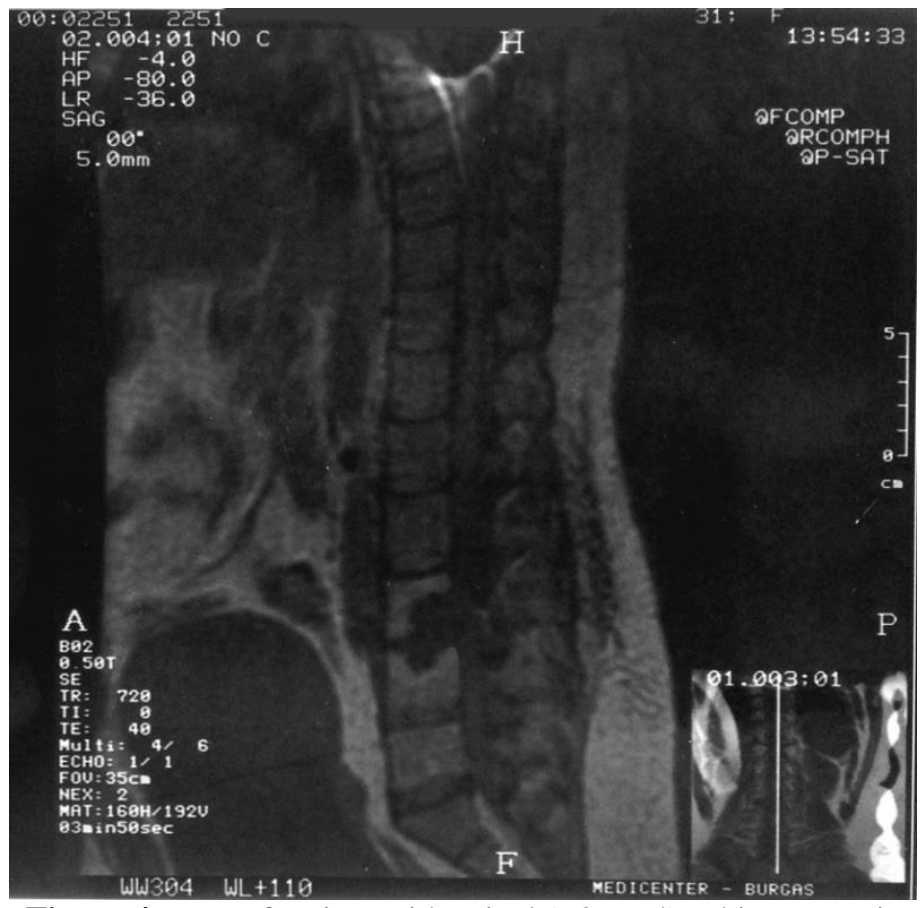

Figure 4. MRI of patient with spinal (L3 - L4) echinococcosis 
The case of lumbar localization there was 36 years old patient with a complaint of gradually increasing (about 2 months) back pain, as well as weakness and numbness of the lower limbs. Neurological examination revealed severe lower paraparesis and sensory level L3. MRI study of lumbar spine showed multi-lobular lesion occupying the vertebral bodies of L3 L4 (Figure 4). Ultrasonography of abdomen, chest X-ray and cranial CT were negative for any systemic foci. Serological test (ELISA) was also negative. The patient underwent L3 to L4 laminectomy. Multiple pearly white cysts were found in the extradural space compressing the dural sac. All the cysts were extirpated without rupture. The operative field was soaked with hydrogen peroxide wetted patties for a few minutes and then washed with normal saline. Histopathological examination confirmed the diagnosis of hydatid cyst.

Postoperative period was uneventful in all of the cases and all patients experienced a regress of the neurological deficit until dehospitalisation. Postoperative preventive chemotherapy with Zentel was carried in doses $10 \mathrm{mg} / \mathrm{kg}$ twice daily with meals for three four cycles (each cycle consists of 28 days and 2-3 days - pause). In one of the cases of cerebral and both cases with spinal localization, the pre- and postoperative laboratory tests and CT scans of the thorax and abdomen failed to demonstrate any lung or liver lesions. Thus, primary echinococcis of the brain and spine was diagnosed. In all other patients imaging studies revealed lesions in the liver, which were subjected to surgery. In none of the patients postoperatively were not identified recurrent cerebral or spinal hydatid cysts.

\section{DISCUSSION}

Cerebral hydatid disease is a rare type of space-occupying lesions of the brain. It occurs 2-3 times more common in children than in adults [23-25]. In the majority of cases, cerebral echinococcosis is accompanied by lesions in lung or liver. Cerebral echinococcosis is usually caused by hematogenic spreading of echinococcal larves forming primary hydatid cysts, predominantly located in the territory of the internal carotid artery [20]. The spinal form of hydatide disease either occurs by direct extension from a pulmonary infestation [21], or begins less often primarily in the vertebral body [15]. Isolated affection of both the brain or the spine is an exception [11, 19]. In a diagnostic term the cerebral hydatid cysts presents with characteristic features on pre-operative cerebral CT scans and are therefore easily diagnosed $[20,22]$. On CT scans they usually presents as huge spherical, homogenous lesions with clearly defined borders, a considerable mass effect but no relevant perifocal edema (Figure 1). The sharp delineation of the cyst and the absence of perifocal edema allow it to be distinguished from brain abscess or tumor [20, 26, 27]. Due to the typical representation of hydatid cysts on CT study, MRI scans are rarely performed in patients with cerebral hydatid disease [28]. However, in many cases the diagnosis comes late, after exhaustion of adaptation capabilities of the brain. The reason for this must be observed in the absence of echinococcosis in differential diagnostic term of thinking mainly because of its rarity. Surgical resection is the therapy of choice in both the cerebral and spinal echinococcosis. Accurate pre-operative diagnosis is essential, as intra-operative rupture of the cyst will result in spreading of the disease. Therefore, during surgery should pay particular attention to prevent intra-operative rupture of the hydatid cyst and the subsequent development of multiple secondary cysts. In our cases with cerebral localization, after punctural draining of the cystic content, the chitin capsule was removed en bloc. In cervico-occipital localization the topic of the process allows dissection and total extirpation of the cyst without draining the cystic contents. In the case of lumbar localization a multitude of small cysts were extirpated separately, without rupture. Control imaging 6 months and 1 year after surgery failed to demonstrate recurrent cerebral or spinal cysts. There are some debates regarding the association of cerebral and spinal hydatid disease with extracrnial cysts, some authors have reported a high percentage of other organs involvement [29-31], while others do not agree [23, 32]. Ameli N. and K. Abbassioun noted that 80$90 \%$ of cerebral hydatid diseases were accompanied by involvement of other organs at autopsy examinations, while in clinical practice; concomitant extracranial cysts were not often demonstrated. In 3 of presented cases: the one with cerebral and both cases with spinal localization all pre- and postoperative examinations - the laboratory tests, sonography and imaging studies were negative in identifying hydatid cysts in other organs. In all other patients imaging studies revealed lesions in the liver, which were subjected to surgery.

Usually infection occurs early in childhood [10, 32-34]. Since brain has a softer tissue, a hydatid cyst in brain grows faster than in other organs. Thus, when hydatid cyst of the brain is large enough to produce symptoms, the cysts 
in other organs are too small to be detected by clinical and radiological evaluations. Some of these small cysts may not be detected until 20 to 30 years after diagnosis of hydatid disease [26]. Furthermore, this diagnosis usually requires post-operative medication that can eradicate the possible small cysts in other organs. In our patients, postoperative treatment was held with Zentel in doses $10 \mathrm{mg} / \mathrm{kg}$ for three -four cycles (each cycle consists of 28 days and 2-3 days - pause). It should be borne in mind that immune system can inhibit the growth of the larvae in other tissues and organs except for CNS. In addition, the presence of patent ductus arteriosus, which might remain for several months after birth, may explain why primary cerebral hydatid disease is more common in childhood [12, 30, 33-36]. Such a role could be assumed for patent foramen ovale, which is present in $25-30 \%$ of individuals [37].

\section{REFERENCES}

1. Ma Z-L, Ma L-G, Ni Y. Cerebral alveolar echinococcosis: A report of two cases. Clin Neurol Neurosurg, 2012.

2. Annual epidemiological report Reporting on 2011 surveillance data and 2012 epidemic intelligence data, ECDC, 2013, 80 $-83$

3. Filipov, F. Echinococcus cerebri contributing to operative treatment. Publishing Sofia University, Faculty of Medicine, XXV, 1945-1946, pp. 153-193.

4. Filipov, F. Brain echinococcus. Surgery and Orthopedics, 2, 1949, 2-3, 131-132.

5. Nikiforov, S., V. Boeva. Echinococcosis. Sofia, "Medicine and Physical Culture", 1983, p 234 (pp. 111-115, 123).

6. Todorov, T., V. Boeva. Human echinococcosis in Bulgaria: a comparative epidemiological analysis. Bull. WHO, 1999, 77, 2, 110-118.

7. Todorov. T. and V. Boeva. Echinococcosis in children and adolescents in Bulgaria: a comparative study. Annals of Tropical Medicine\&Parasitology, 2000, 94, 2, 135144.

8. Ramsey PG, Plorde JL. Cestode (tapeworm) infections. In: Braunwald E, Isselbacher KI, Petersdorf RG, Wilson JD, Martin JB, Fauci AS (eds.) Harrison's principles of internal medicine. McGraw Hill, New York, 1987, pp 825-829.

9. Tuzun M, Altinors N, Arada IS, et al. Cerebral hydatid disease CT and MR findings. Clin Imaging, 2002;26:353-7.

10. Kammerer WS. Echinococcosis. In: Vinken PJ, Bruyn GW, Klawans HL (eds)
Handbook of Clinical neurology, vol 52. Elsevier, Amsterdam, 1988, pp 523-527.

11.Carrea R, Dowling E Jr, Guevara JA. Hydatid cysts in childhood. Prog Pediatr Surg., 1975 5:1-35

12.Ergün R, Ökten AI, Yüksel $M$, Gül $B$, Evliyaoglu C, Ergüngör $\mathrm{F}$, Taskin $\mathrm{Y}$. Orbital hydatid cysts: report of four cases. Neurosurg Rev., 1997, 20:33-37.

13.Benzagmout M., Kamaoui I., Chakour K., Chaoui M.E.Primary spinal epidural hydatid cyst with intrathoracic extension. Neurosciences 2009; Vol. 14 (1), p 81-83.

14.Bavbek M, Inci S, Tahta K, Bertan V. Primary multiple spinal extradural hydatid cysts. Case report and review of the literature [corrected]. Paraplegia 1992; 30: 517-519.

15.Charles RW, Govender S, Naido O. Echinococcal infection of the spine with neural involvement. Spine 1988; 13: 47-49.

16. Fiennes AG, Thomas DG. Combined medical and surgical treatment of spinal hydatid disease: a case report. J Neurol Neurosurg Psychiatry 1982; 45: 927-930.

17.Kaoutzanis M, Anagnostopoulos D, Apostolou A. Hydatid disease affecting the vertebrae. Acta Neurochir (Wien) 1989; 98 : 60-65.

18.Özer AF, Özek MM, Pamir MN, Erzen C. Magnetic resonance imaging in the diagnosis of spinal hydatid cyst disease. Case report. Paraplegia 1993; 31: 338-340.

19. Hatzidakis G. Hydatidosis of the central nervous system. Iatriki, 1969, 15:566-576.

20.Nanassis K., Alexiadou-Rudolf C., Tsitsopoulos P., Tzioufa V., Petsas G., Grigoriou K. Solid cerebral echinococcosis mimicking a primary brain tumor. Neurosurg Rev.,1999, 22: 58-61.

21.Tekkok IH, Benli K. Primary spinal extradural hydatid disease: report of a case with magnetic resonance characteristics and pathological correlation. Neurosurgery 1993; 33: 320-323.

22. Awasthy N, Chand K. Primary hydatid disease of the spine: an unusual case. $\mathrm{Br} J$ Neurosurg 2005; 19: 425-427.

23.Daskas AN, Aggelopoulos E, Tzoufi M. Accidental drainage of a cerebral hydatid cyst into the peritoneal cavity. Ped Infec Dis J. 2004; 23(7):685-6.

24.Popli MB, Khudale B. Primary multiple hydatid cysts of the brain. Australasian Radiol 1998;42(1):90-91.

25.Erashin Y, Mutluer S, Guzelbag E. Intracranial hydatid cysts in children. Neurosurg. 1993;33(2):219-24.

26. Abassioun K, Rahmat H, Ameli NO. Computerized tomography in hydatic cyst 
of the brain. J Neurosurg., 1979, 49:408411.

27.Rudwan MA, Khaffaji S. CT of cerebral hydatid disease. Neuroradiology, 1988, 30:496-499.

28.Bensaid AH, Dietemann JL, Palavesa MM de la, Klinkert A, Kastler B., Gangi A, Jacquet F, Cattin F. Intracranial alveolar echinococcosis: $\mathrm{CT}$ and MRI. Neuroradiology, 1994, 36: 289-291.

29.Tuzun Y, Kadioglu HH, Izci Y, et al. The clinical, radiological and surgical aspects of cerebral hydatid. Pediatr Neurosurg. 2004;40(4):155-60.

30.Ray M, Singhi PD, Pathak A, et al. Primary multiple intracerebral echinococcosis in a young child. J Trop Pediatr. 2001;51(1): 59-61.

31.Farid Radmenesh, Farideh Nejat. Primary Cerebral Hydatid Cyst: Two Cases Report. Iran J Pediatr. Mar 2008; Vol 18 (No 1); Pp 83-86.

32.Ameli NO, Abbassioun K. Hydatid disease of central nervous system. 1st ed (Persian). Tehran; Ketabsara. 1995.
33. Vatansever M, Biliciler B, Aladag MA, Colak A. A huge cerebral hydatid cyst associated with a small liver cyst: a comparison of growth rates and sizes. Neurosurg Rev., 1996, 12:123-126.

34.Zahawi HM, Hameed OK, Abalkhail AA. The possible role of the age of the human host in determining the localization of hydatid cysts. Annals Trop Med Parasitol. 1999; 93(6):621-7.

35.Griponissiotis B, Vasilakis D, Tsitsopoulos P. Some observations on cerebral hydatid disease. Seara Med Neurochir (Sao Paolo), 1979, 8:403-410.

36. Gupta S, Desai K, Goel A. Intracranial hydatid cyst: a report of five cases and review of literature. Neurol India 1999; 47(3):214-7.

37. Griffin $\quad$ BP. Transesophageal echocardiography. In: Griffin BP, Topol EJ (eds). Textbook of Cardiovascular Medicine. 2nd ed. Philadelphia; Lippincott Williams \& Wilkins. 2002; P:1175. 